\title{
Power increase of the power plant with single-circuit ORC plant with a wet medium, supplied with water in appropriate proportions from the Lower and Middle Triassic Reservoirs
}

\author{
Stawomir Wiśniewski ${ }^{1, *}$, Gabriela Sołtysik ${ }^{1}$, and Władysław Nowak ${ }^{1}$ \\ ${ }^{1}$ West Pomeranian University of Technology, Chair of Thermal Engineering, Al. Piastów 19, 70-310, Szczecin, Poland
}

\begin{abstract}
This article presents an analysis of the efficiency of the ORC power plant with a wet circulating medium. The power plant is supplied from two heat sources, which are geothermal water streams obtained from the Lower Triassic and Middle Triassic Reservoirs. In the ORC system, it was assumed that one of these streams is directed to the superheater and the other to the evaporator. In the work, two variants of ORC power supply were considered. The first one, in which the maximum stream of water from the Middle Triassic Reservoir $\dot{\mathrm{m}}_{\mathrm{g} 2}=55 \mathrm{~kg} / \mathrm{s}$ at a temperature of $\mathrm{T}_{\mathrm{g} 1}^{2}=104^{\circ} \mathrm{C}$ powers the evaporator, while the water stream from the Lower Triassic Reservoir $\dot{\mathrm{m}}_{\mathrm{g} 1}=25 \mathrm{~kg} / \mathrm{s}$ at a temperature of $\mathrm{T}_{\mathrm{g} 1}^{1}=128^{\circ} \mathrm{C}$ powers the superheater. In the second variant, the maximum water stream from the Lower Triassic Reservoir $\dot{\mathrm{m}}_{\mathrm{g} 1}=25$ $\mathrm{kg} / \mathrm{s}$ and a temperature of $\mathrm{T}_{\mathrm{g} 1}^{1}=128^{\circ} \mathrm{C}$ feeds the evaporator, while the water stream from the Middle Triassic Reservoir $\dot{\mathrm{m}}_{\mathrm{g} 2}$ at a temperature of $\mathrm{T}_{\mathrm{g} 1}^{2}=104^{\circ} \mathrm{C}$ supplies the superheater. In both variants, the geothermal water stream directed to the superheater is the size resulting from ORC plant operation and cannot exceed the maximum flow value for a given geothermal reservoir. The following working substances were taken into account in the analysis: cyclopropane, R143a, R32, propylene, R22, propane, R134a. The analysis carried out showed that in the ORC power plant with a two-source supply the maximum system power was obtained in the case of the first variant for the working medium R143a.
\end{abstract}

\section{Introduction}

In recent years, we have been dealing with a constant increase in energy consumption [1]. The need to cover the growing demand for energy forces the search for new sources of energy or increase the use of existing resources of fossil fuels and renewable energy carriers. Environmental degradation associated with the emission of pollutants from the energy sector using conventional energy carriers as well as international obligations [2] are forcing more and more interest in renewable energy sources. For this reason, in this paper an attempt to assess the efficiency of the ORC plant operation using geothermal resources as a heat source was made. In Poland, the resources of this energy are used to a small extent, and existing geothermal plants use it only for heating purposes [3]. Geothermal waters with a temperature of $100-130^{\circ} \mathrm{C}$ do not create the possibility of using these resources to generate electricity in a classical steam power plant (with geothermal water as a circulating fluid). In this temperature range of the heat carrier, it is real to use the ORC (Organic Rankine Cycle) power plant. In the literature, there are a lot of works on the ORC power plant. These are the works, among others, in which issues related to the evaluation of the efficiency of ORC systems supplied from different heat sources, their operation and the technical solutions used have been presented [4-7].

In the ORC plant, the circulating factor is a suitable organic substance, characterized by high saturation pressure of several MPa at low evaporation temperatures (below $100^{\circ} \mathrm{C}$ ). Such substances are commonly used in refrigeration systems. The analysis of the properties of circulating fluids used in ORC systems was presented, among others, in [8-11]. These works clearly show that the right choice of a fluid has a significant impact on the ORC power plant efficiency.

Apart from the analysis of single-circuit ORC systems supplied from one source of heat, the literature also includes works on systems supplied from many heat sources. The works in which the ORC systems supplied from many sources were analyzed include, among others, [6, 13-15]. A characteristic feature of the systems analyzed in these works was that they consisted of many separate ORC circuits. The paper [16] presents an assessment of the effectiveness of a geothermal power plant with a single-circuit ORC power plant with a twosource power supply. The assessment of the efficiency of this plant, including the power value $\mathrm{N}_{\mathrm{C}-\mathrm{R}}$ and the thermal efficiency of the Rankine cycle $\eta_{\mathrm{C}-\mathrm{R}}$, was carried out for the selected dry medium and wet agent. In the analyzed ORC system [16], as well as in this paper,

Corresponding author: Slawomir.Wisniewski@zut.edu.pl 
geothermal water extracted from the Lower Triassic Reservoir and the Middle Triassic Reservoir were assumed as the heat sources.

It was assumed in the work [16] that in the case of the ORC plant with a dry working medium, the mass stream of geothermal water with higher temperature supplies the evaporator, and the mass stream of geothermal water with lower temperature feeds the preheater. In the case of a power plant with a wet working medium, the mass stream of geothermal water with a higher temperature feeds the superheater, and the stream of geothermal water with lower temperature powers the evaporator.

This paper presents the evaluation of ORC power plant efficiency with a wet circulating factor, supplied from two heat sources, i.e. geothermal water obtained from the Lower Triassic Reservoir and the Middle Triassic Reservoir, including two variants of this power supply.

In the first variant of feeding the ORC system, the maximum flow of geothermal water obtained from the Middle Triassic Reservoir $\dot{\mathrm{m}}_{\mathrm{g} 2}$ at a temperature of $\mathrm{T}_{\mathrm{g} 1}^{2}$ feeds the evaporator. The size of mass stream of geothermal water from the Lower Triassic Reservoir $\dot{\mathrm{m}}_{\mathrm{g} 1}$ with the supply temperature $\mathrm{T}_{\mathrm{g} 1}^{1}$ supplying the superheater was adjusted to the operating parameters of the analyzed ORC plant. The size of this stream was determined from the dependence (7) presented in the calculation methodology, however, it cannot exceed the maximum mass stream $\dot{\mathrm{m}}_{\mathrm{g}}=25 \mathrm{~kg} / \mathrm{s}$.

In the second variant, the maximum stream of geothermal water from the Lower Triassic Reservoir with the stream $\dot{\mathrm{m}}_{\mathrm{g} 1}$ and the temperature $\mathrm{T}_{\mathrm{g} 1}^{1}$ supplies the evaporator. The size of the mass stream of geothermal water from the Middle Triassic Reservoir, feeding the superheater, was adapted to the operating parameters of the analyzed ORC plant. The size of this stream of geothermal water $\dot{\mathrm{m}}_{\mathrm{g} 2}$ was determined from dependence (17), however, it cannot exceed the maximum mass stream $\dot{\mathrm{m}}_{\mathrm{g}}=55 \mathrm{~kg} / \mathrm{s}$.

The exact description of the ORC system analyzed, along with the diagrams are presented in the next part of the work..

\section{System description}

The system under consideration is an ORC power plant with a two-source power supply. These sources of heat are two streams of geothermal water, the first extracted from the Lower Triassic Reservoir and the second extracted from the Middle Triassic Reservoir. The power plant comprises the preheater 5, evaporator 6, superheater 7 , turbo-generator 2 , condenser 3 , circulation pump 4. It has been assumed that the circulating fluid in the power plant is a working medium from the group of so-called wet working fluids. The evaporation process of this factor in the ORC plant is carried out at a temperature of $67^{\circ} \mathrm{C}$ and the condensation process at a temperature of $29^{\circ} \mathrm{C}$. The analysis includes seven working fluids: cyclopropane, R143a, R32, propylene,
R22, propane, R134a. The analysis of the efficiency of the ORC plant operation with the above-mentioned factors was carried out for two variants of system supply from two different temperature heat sources. In the first variant, carried out in accordance with the diagram shown in Figure 1, the stream of water from the Lower Triassic Reservoir $\dot{\mathrm{m}}_{\mathrm{g} 1}$ is directed to the superheater, whereas the water stream $\dot{\mathrm{m}}_{\mathrm{g} 2}$ from the Middle Triassic Reservoir is directed to the evaporator. These streams, after leaving the superheater and evaporator are combined before the preheater. Therefore, a total stream of geothermal water $\dot{\mathrm{m}}_{\mathrm{g} 3}$, with a temperature of $70^{\circ} \mathrm{C}$, is directed to the preheater. After leaving the preheater, the cooled water returns to the Triassic Reservoirs. In each of the heat exchangers geothermal water gives energy to the organic medium. The working fluid first goes to the preheater 5, where it receives heat from the water stream and heats up from the condensation temperature to the evaporation temperature. Then the fluid goes to the evaporator 6 , where it is evaporated, and then in the form of dry saturated steam is directed to the next heat exchanger, that is superheater 7 . In the superheater 7 , the temperature of the steam increases. Then the superheated steam goes to the turbo-generator 2, where it expands to the pressure corresponding to the condensing pressure. After leaving the turbo-generator 2 the steam goes to the condenser 3. As a result of cooling, the circulating medium in the condenser 3 is condensed. The condensate liquid by means of circulating pump 4 is conveyed into the preheater 5 , where it is heated to the evaporation temperature and the cycle of particular transformations is repeated.

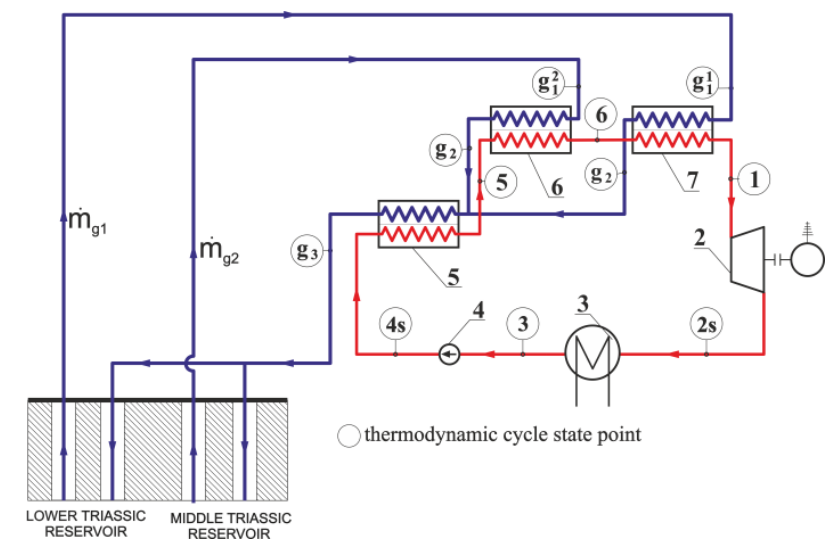

Fig. 1. ORC plant diagram with a two-source power supply for the first variant.

The second variant analyzed in the work is the ORC system operating in accordance with the scheme shown in Figure 2. The main difference between the principle of operation and the first variant is that in the second variant the geothermal water stream from the Lower Triassic Reservoir $\dot{\mathrm{m}}_{\mathrm{g} 1}$ is directed to the evaporator, whereas the stream $\dot{\mathrm{m}}_{\mathrm{g} 2}$ water from the Middle Triassic Reservoir is directed to the superheater.

The cycle of thermodynamic transformations carried out in individual ORC devices is presented in Figure 3.

The transformations shown in Figure 3 are carried out in the following devices: 
1-2s: isentropic expansion of the steam turbine (to saturation state),

2s-3: condensation of steam in the condenser,

3-4s: isentropic increase of working fluid pressure in the pump,

4s-5: isobaric preheating of the working liquid in the preheater to the saturation state,

5-6: isobaric-isothermal evaporation of the liquid in the evaporator,

6-1: isobaric superheated steam in the superheater.

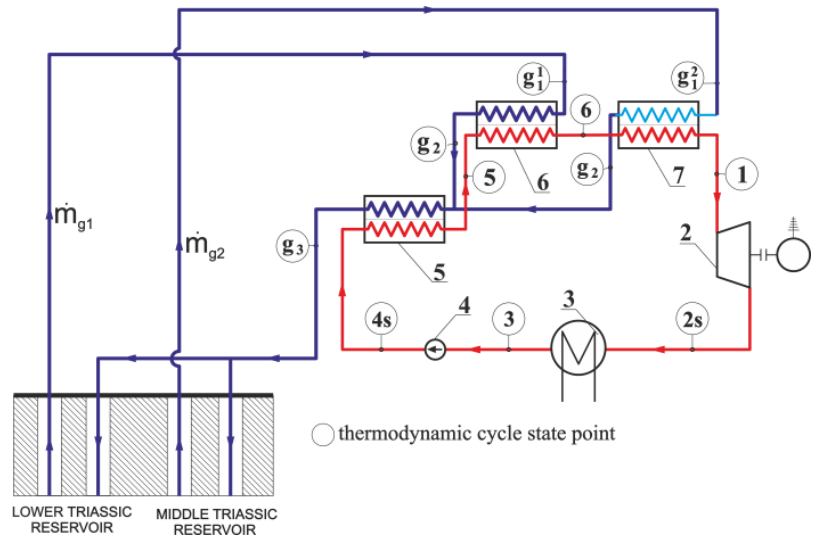

Fig. 2. ORC plant diagram with a two-source power supply for the second variant.

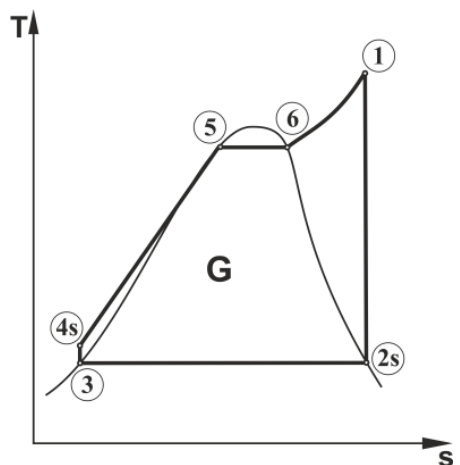

Fig. 3. T-s diagram of the Rankine cycle.

\section{Methodology of calculations}

The paper presents the assessment of the efficiency of the power plant operation with a single-circuit ORC power plant with a two-source power supply. As a source of heat, the Lower Triassic Reservoir and the Middle Triassic Reservoir were adopted. For calculations it was assumed that in the case of the Lower Triassic Reservoir the maximum mass flow of geothermal water is $\dot{\mathrm{m}}_{\mathrm{g} 1}=25 \mathrm{~kg} / \mathrm{s}$, and the temperature of the extracted water is $\mathrm{T}_{\mathrm{g} 1}^{1}=128^{\circ} \mathrm{C}$. In the case of the Middle Triassic Reservoir, the maximum mass flow of geothermal water is $\dot{\mathrm{m}}_{\mathrm{g} 2}=55 \mathrm{~kg} / \mathrm{s}$, and the temperature of the extracted water is $\mathrm{T}_{\mathrm{gl}}^{2}=104^{\circ} \mathrm{C}$. It has been assumed that the geothermal water temperature at the outlet from the superheater and evaporator is $\mathrm{T}_{\mathrm{g} 2}=70^{\circ} \mathrm{C}$.

For the above-mentioned temperatures, the appropriate specific enthalpies appearing in the energy balance equations of the geothermal water as an energy carrier have been identified $h_{\mathrm{g} 1}^{1}\left(\mathrm{~T}_{\mathrm{g} 1}^{1}\right), \mathrm{h}_{\mathrm{g} 2}\left(\mathrm{~T}_{\mathrm{g} 2}\right), \mathrm{h}_{\mathrm{g} 3}\left(\mathrm{~T}_{\mathrm{g} 3}\right)$.
After adopting the type of working medium on the basis on the specific enthalpy in the characteristic points of the Rankine cycle, the proper enthalpies of the overheating $\Delta \mathrm{h}_{\text {superh }}$, evaporation $\Delta \mathrm{h}_{\text {evap }}$, preheating $\Delta \mathrm{h}_{\text {preh }}$ were determined from the following dependencies:

$$
\begin{gathered}
\Delta \mathrm{h}_{\text {superh }}=\mathrm{h}_{1}-\mathrm{h}_{6} \\
\Delta \mathrm{h}_{\text {evap }}=\mathrm{h}_{6}-\mathrm{h}_{5} \\
\Delta \mathrm{h}_{\text {preh }}=\mathrm{h}_{5}-\mathrm{h}_{4 \mathrm{~s}}
\end{gathered}
$$

where: $\mathrm{h}$ - specific enthalpy of the organic factor at the characteristic points of the Rankine cycle.

In the first variant, the ORC power plant is supplied with a stream of geothermal water $\dot{\mathrm{m}}_{\mathrm{g} 1}$ from the Lower Triassic Reservoir with a temperature $\mathrm{T}_{\mathrm{g} 1}^{1}$, which is directed to the superheater, and the geothermal water stream $\dot{\mathrm{m}}_{\mathrm{g} 2}$ from the Middle Triassic Reservoir with temperature $\mathrm{T}_{\mathrm{g} 1}^{2}$, which feeds the evaporator. In order to perform thermal-flow calculations for the first variant, the energy balance equations of three heat exchangers in the following form have been used:

for superheater:

$$
\dot{\mathrm{m}}_{\mathrm{g} 1}\left[\mathrm{~h}_{\mathrm{g} 1}^{1}\left(\mathrm{~T}_{\mathrm{g} 1}^{1}\right)-\mathrm{h}_{\mathrm{g} 2}\left(\mathrm{~T}_{\mathrm{g} 2}\right)\right]=\dot{\mathrm{m}}_{\mathrm{n}} \Delta \mathrm{h}_{\text {superh }}
$$

for evaporator:

$$
\dot{\mathrm{m}}_{\mathrm{g} 2}\left[\mathrm{~h}_{\mathrm{g} 1}^{2}\left(\mathrm{~T}_{\mathrm{g} 1}^{2}\right)-\mathrm{h}_{\mathrm{g} 2}\left(\mathrm{~T}_{\mathrm{g} 2}\right)\right]=\dot{\mathrm{m}}_{\mathrm{n}} \Delta \mathrm{h}_{\mathrm{evap}}
$$

for preheater:

$$
\dot{\mathrm{m}}_{\mathrm{g} 3}\left[\mathrm{~h}_{\mathrm{g} 2}\left(\mathrm{~T}_{\mathrm{g} 2}\right)-\mathrm{h}_{\mathrm{g} 3}\left(\mathrm{~T}_{\mathrm{g} 3}\right)\right]=\dot{\mathrm{m}}_{\mathrm{n}} \Delta \mathrm{h}_{\mathrm{preh}}
$$

In order to determine the mass flow of geothermal water $\dot{\mathrm{m}}_{\mathrm{g} 1}$ from the Lower Triassic Reservoir feeding the superheater, the dependences (4) and (5) were divided on two sides. After performing the appropriate transformations, the expression for stream $\dot{\mathrm{m}}_{\mathrm{g} 1}$ supplying the superheater has got the following form (7):

$$
\dot{\mathrm{m}}_{\mathrm{g} 1}=\left(\frac{\left(\mathrm{h}_{\mathrm{g} 1}^{2}-\mathrm{h}_{\mathrm{g} 2}\right)}{\left(\mathrm{h}_{\mathrm{g} 1}^{1}-\mathrm{h}_{\mathrm{g} 2}\right)} \frac{\Delta \mathrm{h}_{\text {superh }}}{\Delta \mathrm{h}_{\text {evap }}}\right) \dot{\mathrm{m}}_{\mathrm{g} 2}
$$

Next, after adding dependencies (4) and (5) respectively and performing the relevant transformations, the dependence on the mass stream of the working medium of the power plan $\dot{\mathrm{m}}_{\mathrm{n}}$ was determined:

$$
\dot{\mathrm{m}}_{\mathrm{n}}=\frac{\dot{\mathrm{Q}}_{\text {superh }}+\dot{\mathrm{Q}}_{\text {evap }}}{\left(\Delta \mathrm{h}_{\text {superh }}+\Delta \mathrm{h}_{\text {evap }}\right)}
$$

The heat flows supplied to the superheater $\dot{Q}_{\text {superh }}$ and the evaporator $\dot{Q}_{\text {evap }}$ which appeared in the equation (8) were determined after using the left sides of dependences (4) and (5).

The water temperature $\mathrm{T}_{\mathrm{g} 3}$ leaving the preheater is higher than the temperature of the medium at the point $\mathrm{T}_{4 \mathrm{~s}}$ by $\Delta \mathrm{T}=3 \mathrm{~K}$.

$$
\mathrm{T}_{\mathrm{g} 3}=\mathrm{T}_{4 \mathrm{~s}}+\Delta \mathrm{T}
$$


The specific enthalpy of water $\mathrm{h}_{\mathrm{g} 3}$ on the outflow from the preheater was read from the Refprop [17] program on the basis of temperature $\mathrm{T}_{\mathrm{g} 3}$.

The mass flow of water $\dot{\mathrm{m}}_{\mathrm{g} 3}$ leaving the preheater was determined on the basis of the balance equation for the preheater (6):

$$
\dot{\mathrm{m}}_{\mathrm{g} 3}=\frac{\dot{\mathrm{m}}_{\mathrm{n}} \Delta \mathrm{h}_{\mathrm{preh}}}{\left[\mathrm{h}_{\mathrm{g} 2}\left(\mathrm{~T}_{\mathrm{g} 2}\right)-\mathrm{h}_{\mathrm{g} 3}\left(\mathrm{~T}_{\mathrm{g} 3}\right)\right]}
$$

The heat flow supplied to the power plant $\dot{\mathrm{Q}}_{\mathrm{d}}$, is the sum of heat fluxes that are fed to the superheater $\dot{\mathrm{Q}}_{\text {superh }}$, the evaporator $\dot{\mathrm{Q}}_{\mathrm{par}}$ and the preheater $\dot{\mathrm{Q}}_{\text {preh }}$ :

$$
\dot{\mathrm{Q}}_{\mathrm{d}}=\dot{\mathrm{Q}}_{\text {superh }}+\dot{\mathrm{Q}}_{\text {evap }}+\dot{\mathrm{Q}}_{\text {preh }}
$$

The dependence on the power plant capacity $\mathrm{N}_{\mathrm{C}-\mathrm{R}}$ takes the following form:

$$
\mathrm{N}_{\mathrm{C}-\mathrm{R}}=\mathrm{l}_{\mathrm{C}-\mathrm{R}} \dot{\mathrm{m}}_{\mathrm{n}}
$$

where: $1_{C-R}=1_{\text {turbine }}-1_{\text {pump }}$ - unit work of the Rankine cycle. The power plant efficiency $\eta_{C-R}$ was determined from the following formula:

$$
\eta_{\mathrm{C}-\mathrm{R}}=\frac{\mathrm{N}_{\mathrm{C}-\mathrm{R}}}{\dot{\mathrm{Q}}_{\mathrm{d}}}
$$

In the second variant, the ORC power plant is also supplied with geothermal water from the Lower Triassic Reservoir with mass flow $\dot{\mathrm{m}}_{\mathrm{g} 1}$ and temperature $\mathrm{T}_{\mathrm{g} 1}^{1}$, with the difference that this stream is directed to the evaporator, and geothermal water from the Middle Triassic Reservoir with the stream $\dot{\mathrm{m}}_{\mathrm{g} 2}$ and temperature $\mathrm{T}_{\mathrm{g} 1}^{2}=104^{\circ} \mathrm{C}$ is directed to the superheater.

In order to perform thermal and flow calculations for the second variant, energy balance equations of three heat exchangers are used, which take the form:

for superheater:

$$
\dot{\mathrm{m}}_{\mathrm{g} 2}\left[\mathrm{~h}_{\mathrm{g} 1}^{2}\left(\mathrm{~T}_{\mathrm{g} 1}^{2}\right)-\mathrm{h}_{\mathrm{g} 2}\left(\mathrm{~T}_{\mathrm{g} 2}\right)\right]=\dot{\mathrm{m}}_{\mathrm{n}} \Delta \mathrm{h}_{\text {superh }}
$$

for evaporator:

$$
\dot{\mathrm{m}}_{\mathrm{g} 1}\left[\mathrm{~h}_{\mathrm{g} 1}^{1}\left(\mathrm{~T}_{\mathrm{g} 1}^{1}\right)-\mathrm{h}_{\mathrm{g} 2}\left(\mathrm{~T}_{\mathrm{g} 2}\right)\right]=\dot{\mathrm{m}}_{\mathrm{n}} \Delta \mathrm{h}_{\text {evap }}
$$

for preheater:

$$
\dot{\mathrm{m}}_{\mathrm{g} 3}\left[\mathrm{~h}_{\mathrm{g} 2}\left(\mathrm{~T}_{\mathrm{g} 2}\right)-\mathrm{h}_{\mathrm{g} 3}\left(\mathrm{~T}_{\mathrm{g} 3}\right)\right]=\dot{\mathrm{m}}_{\mathrm{n}} \Delta \mathrm{h}_{\mathrm{preh}}
$$

First, to determine the stream of geothermal water feeding the superheater, the dependence (14) should be divided by (15). After the transformation of these equations, the dependence on the stream of geothermal water $\dot{\mathrm{m}}_{\mathrm{g} 2}$ feeding the superheater is as follows:

$$
\dot{\mathrm{m}}_{\mathrm{g} 2}=\left(\frac{\left(\mathrm{h}_{\mathrm{g} 1}^{1}-\mathrm{h}_{\mathrm{g} 2}\right)}{\left(\mathrm{h}_{\mathrm{g} 1}^{2}-\mathrm{h}_{\mathrm{g} 2}\right)} \cdot \frac{\Delta \mathrm{h}_{\text {superh }}}{\Delta \mathrm{h}_{\text {evap }}}\right) \dot{\mathrm{m}}_{\mathrm{g} 1}
$$

The further calculation algorithm is the same as in the calculation for the first variant.

\section{Calculation results}

All thermal and caloric parameters of circulating factors as well as geothermal water were determined using the basis of organic factors RefProp [17]. Corresponding statements of these values for circulating factors of the ORC power plant and geothermal water circuits are presented in Tables 1 and 2.

Table 1. Comparison of values of temperatures and specific enthalpies in the ORC power plant at characteristic points of circulation for two selected factors for the first and second variant.

\begin{tabular}{|c|c|c|c|c|c|c|c|}
\hline \multirow{2}{*}{ Working fluid } & \multicolumn{7}{|c|}{ Circulation point } \\
\cline { 3 - 8 } & 1 & $2 \mathrm{~s}$ & 3 & $4 \mathrm{~s}$ & 5 & 6 \\
\hline \multirow{2}{*}{$\mathrm{R} 143 \mathrm{a}$} & $\mathrm{T}\left[{ }^{\circ} \mathrm{C}\right]$ & 75,16 & 29,00 & 29,00 & 30,89 & 67,00 & 67,00 \\
\cline { 2 - 8 } & $\mathrm{h}[\mathrm{kJ} / \mathrm{kg}]$ & 417,7 & 399,8 & 245,9 & 248,00 & 232,1 & 392,2 \\
\hline \multirow{2}{*}{$\mathrm{R} 32$} & $\mathrm{~T}\left[{ }^{\circ} \mathrm{C}\right]$ & 91,55 & 29,00 & 29,00 & 31,09 & 67,00 & 67,00 \\
\cline { 2 - 8 } & $\mathrm{h}[\mathrm{kJ} / \mathrm{kg}]$ & 549,3 & 515,9 & 253,4 & 256,2 & 341,9 & 486,3 \\
\hline
\end{tabular}

Table 2. Comparison of the values of temperatures and specific enthalpies of geothermal water at individual points of the power plant for the first and second variant.

\begin{tabular}{|c|c|c|c|c|c|}
\hline \multicolumn{2}{|c|}{ Working fluid } & \multicolumn{4}{|c|}{ Circulation point } \\
\cline { 3 - 6 } \multicolumn{2}{|c|}{} & $\mathrm{g}_{1}^{1}$ & $\mathrm{~g}_{]}^{2}$ & $\mathrm{~g} 2$ & $\mathrm{~g} 3$ \\
\hline \multirow{2}{*}{ R143a } & $\mathrm{T}\left[{ }^{\circ} \mathrm{C}\right]$ & 128 & 104 & 70 & 33,89 \\
\cline { 2 - 6 } & $\mathrm{h}[\mathrm{kJ} / \mathrm{kg}]$ & 537,9 & 436,05 & 293,07 & 142,00 \\
\hline \multirow{2}{*}{$\mathrm{R} 32$} & $\mathrm{~T}\left[{ }^{\circ} \mathrm{C}\right]$ & 128 & 104 & 70 & 34,09 \\
\cline { 2 - 6 } & $\mathrm{h}[\mathrm{kJ} / \mathrm{kg}]$ & 537,9 & 436,05 & 293,07 & 142,85 \\
\hline
\end{tabular}

The obtained calculation results characterizing the ORC power plant efficiency for circulating factors R143a and R22 for the first and the second variant are presented in Tables 3, 4, 5 and 6.

Table 3. Comparison of the results of calculations of the quantities characterizing operation of the ORC power plant of the first variant with the working medium R143a.

\begin{tabular}{|c|c|c|c|c|}
\hline$\Delta \mathrm{h}_{\text {superh }}$ & $\Delta \mathrm{h}_{\text {evap }}$ & $\Delta \mathrm{h}_{\text {preh }}$ & $\Delta \mathrm{h}_{\text {cond }}$ & $\Delta \mathrm{h}_{\mathrm{c}}$ \\
\hline $\mathrm{h}_{1}-\mathrm{h}_{6}$ & $\mathrm{~h}_{6}-\mathrm{h}_{5}$ & $\mathrm{~h}_{5}-\mathrm{h}_{4 \mathrm{~s}}$ & $\mathrm{~h}_{2 \mathrm{~s}}-\mathrm{h}_{3}$ & $\mathrm{~h}_{1}-\mathrm{h}_{4 \mathrm{~s}}$ \\
\hline 25,57 & 69,08 & 75,10 & 153,92 & 169,75 \\
\hline $1_{\text {turbine }}[\mathrm{kW}]$ & $\mathrm{l}_{\text {pump }}[\mathrm{kW}]$ & $\mathrm{l}_{\mathrm{C}-\mathrm{R}}[\mathrm{kW}]$ & \multicolumn{2}{|c|}{$\dot{\mathrm{m}}_{\mathrm{g} 1}[\mathrm{~kg} / \mathrm{s}]$} \\
\hline 17,94 & 2,11 & 15,83 & \multicolumn{2}{|c|}{11,89} \\
\hline$\dot{\mathrm{Q}}_{\text {superh }}[\mathrm{kW}]$ & $\dot{\mathrm{Q}}_{\text {evap }}[\mathrm{kW}]$ & \multicolumn{2}{|c|}{$\dot{\mathrm{m}}_{\mathrm{n}}[\mathrm{kg} / \mathrm{s}]$} \\
\hline 2910,83 & \multicolumn{2}{|c|}{7863,90} & \multicolumn{2}{|c|}{113,84} \\
\hline \multicolumn{2}{|c|}{$\mathrm{T}_{\mathrm{g} 3}\left[{ }^{\circ} \mathrm{C}\right]$} & \multicolumn{2}{|c|}{$\dot{\mathrm{m}}_{\mathrm{g} 3}$} \\
\hline 33,89 & 142,00 & \multicolumn{2}{|c|}{56,59} \\
\hline \multicolumn{2}{|c|}{$\dot{\mathrm{Q}}_{\text {preh }}[\mathrm{kW}]$} & $\dot{\mathrm{Q}}_{\mathrm{d}}[\mathrm{kW}]$ & $\mathrm{N}_{\mathrm{C}-\mathrm{R}}[\mathrm{kW}]$ & $\mathrm{\eta}_{\mathrm{C}-\mathrm{R}}[\%]$ \\
\hline 8549,90 & \multicolumn{2}{|c|}{19324,63} & 1801,84 & 9,32 \\
\hline
\end{tabular}

In order to demonstrate the legitimacy of the proposed ORC plant solution supplied from two heat sources, the power capacity of the ORC power plant supplied from one heat source was calculated. Determining the power of the power plant supplied from one heat source, it was assumed that the maximum available stream of geothermal water from the Lower Triassic Reservoir or the Middle Triassic Reservoir is used. The results of these calculations for all analyzed factors are presented in Table 7. 
Table 4. Comparison of the results of calculations of the quantities characterizing operation of the ORC power plant of the first variant with the R32 working medium.

\begin{tabular}{|c|c|c|c|c|}
\hline$\Delta \mathrm{h}_{\text {superh }}$ & $\Delta \mathrm{h}_{\text {evap }}$ & $\Delta \mathrm{h}_{\text {preh }}$ & $\Delta \mathrm{h}_{\text {cond }}$ & $\Delta \mathrm{h}_{\mathrm{c}}$ \\
\hline $\mathrm{h}_{1}-\mathrm{h}_{6}$ & $\mathrm{~h}_{6}-\mathrm{h}_{5}$ & $\mathrm{~h}_{5}-\mathrm{h}_{4 \mathrm{~s}}$ & $\mathrm{~h}_{2 \mathrm{~s}}-\mathrm{h}_{3}$ & $\mathrm{~h}_{1}-\mathrm{h}_{4 \mathrm{~s}}$ \\
\hline 62,93 & 144,48 & 85,65 & 262,56 & 293,06 \\
\hline $\mathrm{l}_{\text {turbine }}[\mathrm{kW}]$ & $\mathrm{l}_{\text {pump }}[\mathrm{kW}]$ & $\mathrm{l}_{\mathrm{C}-\mathrm{R}}[\mathrm{kW}]$ & \multicolumn{2}{|c|}{$\dot{\mathrm{m}}_{\mathrm{g} 1}[\mathrm{~kg} / \mathrm{s}]$} \\
\hline 33,34 & 2,84 & 30,50 & \multicolumn{2}{|c|}{13,99} \\
\hline$\dot{\mathrm{Q}}_{\text {superh }}[\mathrm{kW}]$ & $\dot{\mathrm{Q}}_{\text {evap }}[\mathrm{kW}]$ & \multicolumn{2}{|c|}{$\dot{\mathrm{m}}_{\mathrm{n}}[\mathrm{kg} / \mathrm{s}]$} \\
\hline 3424,99 & 7863,90 & \multicolumn{2}{|c|}{54,43} \\
\hline $\mathrm{T}_{\mathrm{g} 3}\left[{ }^{\circ} \mathrm{C}\right]$ & $\mathrm{h}_{\mathrm{g} 3}$ & \multicolumn{2}{|c|}{$\dot{\mathrm{m}}_{\mathrm{g} 3}$} \\
\hline 34,09 & 142,85 & \multicolumn{2}{|c|}{31,03} \\
\hline$\dot{\mathrm{Q}}_{\text {preh }}[\mathrm{kW}]$ & \multicolumn{2}{|c|}{$\dot{\mathrm{Q}}_{\mathrm{d}}[\mathrm{kW}]$} & $\mathrm{N}_{\mathrm{C}-\mathrm{R}}[\mathrm{kW}]$ & $\eta_{\mathrm{C}-\mathrm{R}}[\%]$ \\
\hline 4662,00 & \multicolumn{2}{|c|}{15950,89} & 1659,98 & 10,41 \\
\hline
\end{tabular}

Table 5. Comparison of the results of calculations of the quantities characterizing operation of the ORC plant of the second variant with the R143a working medium.

\begin{tabular}{|c|c|c|c|c|c|}
\hline$\Delta \mathrm{h}_{\text {superh }}$ & \multicolumn{2}{|c|}{$\Delta \mathrm{h}_{\text {evap }}$} & $\Delta \mathrm{h}_{\text {preh }}$ & $\Delta \mathrm{h}_{\text {cond }}$ & $\Delta \mathrm{h}_{\mathrm{c}}$ \\
\hline $\mathrm{h}_{1}-\mathrm{h}_{6}$ & \multicolumn{2}{|c|}{$h_{6}-h_{5}$} & $\mathrm{~h}_{5}-\mathrm{h}_{4 \mathrm{~s}}$ & $\mathrm{~h}_{2 \mathrm{~s}}-\mathrm{h}_{3}$ & $\mathrm{~h}_{1}-\mathrm{h}_{4 \mathrm{~s}}$ \\
\hline 25,57 & \multicolumn{2}{|c|}{69,08} & 75,10 & 153,92 & 169,75 \\
\hline $\mathrm{l}_{\text {turbine }}[\mathrm{kW}]$ & \multicolumn{2}{|c|}{$1_{\text {pump }}[\mathrm{kW}]$} & $\mathrm{l}_{\mathrm{C}-\mathrm{R}}[\mathrm{kW}]$ & \multicolumn{2}{|c|}{$\dot{\mathrm{m}}_{\mathrm{g} 1}[\mathrm{~kg} / \mathrm{s}]$} \\
\hline 17,94 & \multicolumn{2}{|c|}{2,11} & 15,83 & \multicolumn{2}{|c|}{15,84} \\
\hline \multicolumn{2}{|c|}{$\mathrm{Q}_{\text {superh }}[\mathrm{kW}]$} & \multicolumn{2}{|c|}{$\dot{\mathrm{Q}}_{\mathrm{evap}}[\mathrm{kW}]$} & \multicolumn{2}{|c|}{$\dot{\mathrm{m}}_{\mathrm{n}}[\mathrm{kg} / \mathrm{s}]$} \\
\hline \multicolumn{2}{|c|}{6119,50} & \multicolumn{2}{|r|}{2265,14} & \multicolumn{2}{|c|}{88,59} \\
\hline \multicolumn{2}{|l|}{$\mathrm{T}_{\mathrm{g} 3}\left[{ }^{\circ} \mathrm{C}\right]$} & \multicolumn{2}{|r|}{$\mathrm{h}_{\mathrm{g} 3}$} & \multicolumn{2}{|c|}{$\dot{\mathrm{m}}_{\mathrm{g} 3}$} \\
\hline \multicolumn{2}{|l|}{33,89} & & 142,00 & \multicolumn{2}{|c|}{44,04} \\
\hline \multicolumn{2}{|c|}{$\dot{\mathrm{Q}}_{\mathrm{preh}}[\mathrm{kW}]$} & & $\dot{\mathrm{Q}}_{\mathrm{d}}[\mathrm{kW}]$ & $\mathrm{N}_{\mathrm{C}-\mathrm{R}}[\mathrm{kW}]$ & $\eta_{\mathrm{C}-\mathrm{R}}[\%]$ \\
\hline \multicolumn{2}{|c|}{6653,33} & & 15037,97 & 1402,15 & 9,32 \\
\hline
\end{tabular}

Table 6. Comparison of the results of calculations of the quantities characterizing operation of the ORC power plant of the second variant with the R32 working medium.

\begin{tabular}{|c|c|c|c|c|}
\hline$\Delta \mathrm{h}_{\text {superh }}$ & $\Delta \mathrm{h}_{\text {evap }}$ & $\Delta \mathrm{h}_{\text {preh }}$ & $\Delta \mathrm{h}_{\text {cond }}$ & $\Delta \mathrm{h}_{\mathrm{c}}$ \\
\hline $\mathrm{h}_{1}-\mathrm{h}_{6}$ & $\mathrm{~h}_{6}-\mathrm{h}_{5}$ & $\mathrm{~h}_{5}-\mathrm{h}_{4 \mathrm{~s}}$ & $\mathrm{~h}_{2 \mathrm{~s}}-\mathrm{h}_{3}$ & $\mathrm{~h}_{1}-\mathrm{h}_{4 \mathrm{~s}}$ \\
\hline 62,93 & 144,48 & 85,65 & 262,56 & 293,06 \\
\hline $\mathrm{l}_{\text {turbine }}[\mathrm{kW}]$ & $\mathrm{l}_{\text {pump }}[\mathrm{kW}]$ & $\mathrm{l}_{\mathrm{C}-\mathrm{R}}[\mathrm{kW}]$ & \multicolumn{2}{|c|}{$\dot{\mathrm{m}}_{\mathrm{g} 1}[\mathrm{~kg} / \mathrm{s}]$} \\
\hline 33,34 & 2,84 & 30,50 & \multicolumn{2}{|c|}{18,64} \\
\hline$\dot{\mathrm{Q}}_{\text {superh }}[\mathrm{kW}]$ & \multicolumn{2}{|c|}{$\dot{\mathrm{Q}}_{\text {evap }}[\mathrm{kW}]$} & \multicolumn{2}{|c|}{$\dot{\mathrm{m}}_{\mathrm{n}}[\mathrm{kg} / \mathrm{s}]$} \\
\hline 6119,50 & 2665,25 & \multicolumn{2}{|c|}{42,36} \\
\hline $\mathrm{T}_{\mathrm{g} 3}\left[{ }^{\circ} \mathrm{C}\right]$ & \multicolumn{2}{|c|}{$\mathrm{h}_{\mathrm{g} 3}[\mathrm{~kW}]$} & \multicolumn{2}{|c|}{$\dot{\mathrm{m}}_{\mathrm{g} 3}[\mathrm{~kg} / \mathrm{s}]$} \\
\hline 34,09 & \multicolumn{2}{|c|}{24,15} \\
\hline$\dot{\mathrm{Q}}_{\text {preh }}[\mathrm{kW}]$ & \multicolumn{2}{|c|}{$\dot{\mathrm{Q}}_{\mathrm{d}}[\mathrm{kW}]$} & $\mathrm{N}_{\mathrm{C}-\mathrm{R}}[\mathrm{kW}]$ & $\mathrm{\eta}_{\mathrm{C}-\mathrm{R}}[\%]$ \\
\hline 3627,86 & \multicolumn{2}{|c|}{12412,60} & 1291,76 & 10,41 \\
\hline
\end{tabular}

Table 7. Comparison of the results of calculations of the quantities characterizing operation of the ORC power plant of the second variant with the R32 working medium.

\begin{tabular}{|c|c|c|c|c|}
\hline \multirow[b]{2}{*}{ Power variant } & \multirow[b]{2}{*}{ W I } & \multirow[b]{2}{*}{ W II } & \multicolumn{2}{|c|}{ Single-source power supply } \\
\hline & & & $\begin{array}{c}\mathrm{T}_{\mathrm{g} 1}^{1}=128^{\circ} \mathrm{C} \\
(25 \mathrm{~kg} / \mathrm{s})\end{array}$ & $\begin{array}{c}\mathrm{T}_{\mathrm{g} 1}^{2}=104^{\circ} \mathrm{C} \\
(55 \mathrm{~kg} / \mathrm{s})\end{array}$ \\
\hline Working fluid & $\begin{array}{l}\mathrm{N}_{\mathrm{C}-\mathrm{R}} \\
{[\mathrm{kW}]}\end{array}$ & $\begin{array}{l}\mathrm{N}_{\mathrm{C}-\mathrm{R}} \\
{[\mathrm{kW}]}\end{array}$ & $\mathrm{N}_{\mathrm{C}-\mathrm{R}}[\mathrm{kW}]$ & $\mathrm{N}_{\mathrm{C}-\mathrm{R}}[\mathrm{kW}]$ \\
\hline Cyclopropane & 1074,5 & 836,2 & 785,1 & 1008,9 \\
\hline R143a & 1801,8 & 1402,2 & 1023,4 & 1315,1 \\
\hline R32 & 1660,0 & 1291,8 & 899,8 & 1156,4 \\
\hline Propylen & 1230,1 & 957,2 & 860,4 & 1105,7 \\
\hline $\mathrm{R} 22$ & 1223,2 & 951,8 & 831,0 & 1067,9 \\
\hline Propan & 1157,6 & 900,8 & 855,2 & 1099,0 \\
\hline $\mathrm{R} 134 \mathrm{a}$ & 1134,3 & 882,7 & 844,8 & 1085,7 \\
\hline
\end{tabular}

The comparison of ORC plant efficiency for the R143a and R32 factors for the first and second variant is shown by means of the bar graph in Figure 4.

The comparison of the power of the ORC power plant for the R143a and R32 factors for the first and second variant is presented by means of a bar graph in Figure 5 .

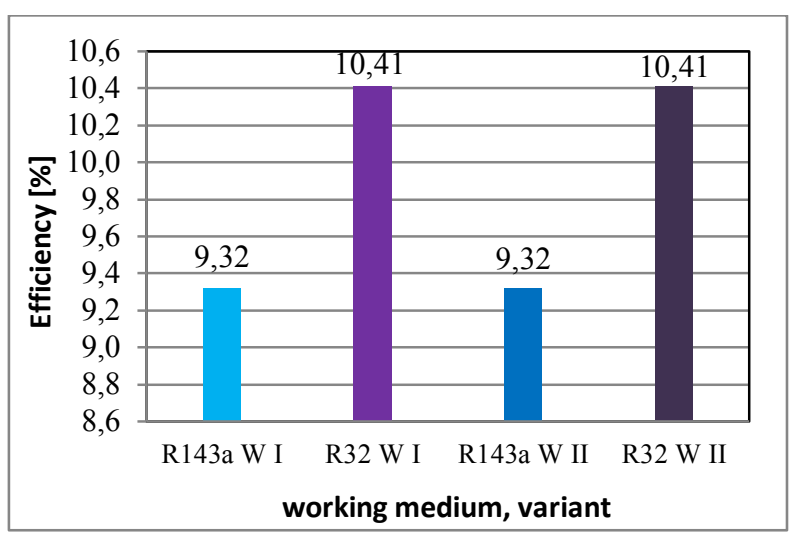

Fig. 4. Efficiency of considered variants.

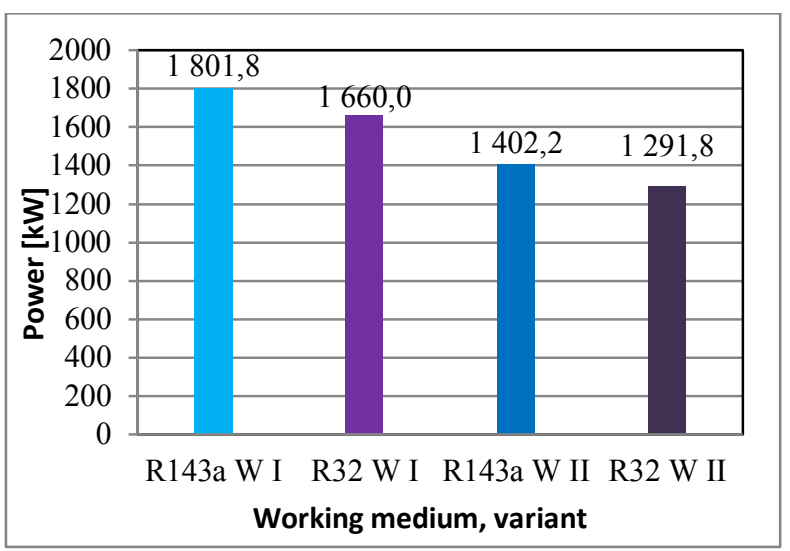

Fig. 5. The power of considered variants.

\section{Conclusion}

In the paper, it was shown that among the two analyzed variants of ORC power station supply with two heat sources, the first power option is more advantageous. Therefore, having at the disposal heat sources similar to those analyzed in this work, the heat carrier with lower temperature and higher mass stream should be directed to the ORC evaporator, and the heat carrier with a higher temperature to the superheater.

The above conclusion is also confirmed by the fact that the obtained power quantities for: cyclopropane, R143a, $\mathrm{R} 32$, propylene, R22, propane and R 134a for the first variant were obtained with incomplete use of the geothermal water stream from the Lower Triassic Reservoir, whose maximum value was assumed at 25 $\mathrm{kg} / \mathrm{s}$. The values of this geothermal water stream for the analyzed working factors, according to the order in which they are listed, are: $\dot{\mathrm{m}}_{\mathrm{gl}}=2,09 \mathrm{~kg} / \mathrm{s}, \quad \dot{\mathrm{m}}_{\mathrm{gl}}=$ $=11,89 \mathrm{~kg} / \mathrm{s}, \quad \dot{\mathrm{m}}_{\mathrm{g} 1}=13,99 \mathrm{~kg} / \mathrm{s}, \quad \dot{\mathrm{m}}_{\mathrm{g} 1}=3,61 \mathrm{~kg} / \mathrm{s}, \quad \dot{\mathrm{m}}_{\mathrm{g} 1}=$ $=4,67 \mathrm{~kg} / \mathrm{s}, \quad \dot{\mathrm{m}}_{\mathrm{g} 1}=1,71 \mathrm{~kg} / \mathrm{s}, \quad \dot{\mathrm{m}}_{\mathrm{g} 1}=1,44 \mathrm{~kg} / \mathrm{s} \quad$ using the maximum flow of geothermal water from the Middle 
Triassic Reservoir $\dot{\mathrm{m}}_{\mathrm{g} 2}=55 \mathrm{~kg} / \mathrm{s}$ directed to the ORC system evaporator. From the above, it also follows that by feeding the ORC system with a heat carrier stream with a lower temperature (geothermal water from the Middle Triassic Reservoir), the required heat carrier stream with a higher temperature delivered to the ORC superheater is much smaller. This makes it possible to take ORC systems supplied from two heat sources into consideration, in which one heat source is, for example, waste heat, and the second heat source is, for example, a biomass-fired boiler (or other fuel). Therefore, the possibility of using such a solution is not limited to using geothermal water as a source of heat.

Analyzing the obtained results of calculations regarding the ORC system with a two-source power supply, it is clearly visible that the type of circulating medium used significantly affects the power of the system. This results directly from the data presented in Table 7 . In the case of the first variant, the highest system power, amounting to $1802,8 \mathrm{~kW}$, was obtained using the circulating medium R143a, whereas the lowest one - 1074,5 kW for the cyclopropane. Using the same heat sources, the power obtained in the analyzed ORC plant with the R143a factor (the first variant) is about $68 \%$ greater than the power obtained in the ORC power plant with the cyclopropane factor. This also confirms the conclusions from many previous works indicating the appropriate choice of working medium in the ORC system. It is suitable not only in terms of temperature parameters of the heat source, but also in terms of maximizing the ORC system power for a given technological solution.

Summarizing the above, it can be concluded that further testing of the ORC power plant with a two-source power supply, aimed at increasing the power, should be continued using only the first power variant.

\section{References}

1. BPStatistical Review of World Energy, June 2018, 67th edition; https://www.bp.com/content/dam/bp/en/corporate/p df/energy-economics/statistical-review/bp-statsreview-2018-full-report.pdf

2. DIRECTIVE 2009/28/EC OF THE EUROPEAN PARLIAMENT AND OF THE COUNCIL of 23 April 2009 on the promotion of the use of energy from renewable sources and amending and subsequently repealing Directives 2001/77/EC and 2003/30/EC

3. B. Kepińska, A review of geothermal energy uses in Poland in 2016-2018, Geological Exploration Technology, Geothermal Energy, Sustainable Development, Vol. 57, (261), pp. 11-27, (in Polish), (2018)

4. Zhang Shengjun, Wang Huaixin, Guo Tao, Performance comparison and parametric optimization of subcritical Organic Rankine Cycle (ORC) and transcritical power cycle system for lowtemperature geothermal power generation, Applied Energy 88, pp. 2740-2754, (2011)
5. H. Ghasemi, M. Paci, A. Tizzanini, A. Mitsos, Modeling and optimization of a binary geothermal power plant, Energy 50, pp 412-428, (2013)

6. A.A. Stachel, S. Wiśniewski, Influence of the type of working fluid in the lower cycle and superheated steam parameters in the upper cycle on effectiveness of operation of binary power plant, Archives of Thermodynamics, Vol. 36, no. 1, pp 111-123, (2015)

7. D. Moyaa, C. Aldásd, P. Kaparajue, Geothermal energy: Power plant technology and direct heat applications, Renewable and Sustainable Energy Reviews 94, pp 889-901, (2018)

8. A. Borsukiewicz-Gozdur, W. Nowak, Comparative analysis of natural and synthetic refrigerants in application to low temperature Clausius-Rankine cycle, Energy 32, 344-352, (2007)

9. O. Badr, S.D. Probert, W.P. O'Callaghan, Selecting a working fluid for a Rankine-cycle engine, Appl. Energ. 21, 1-42, (1985)

10. A.A. Lakew, O. Bolland, Working fluids for lowtemperature heat source, Applied Thermal Engineering 30, pp 1262-1268, (2010)

11. B. Saleh, G. Koglbauer, M. Wendland, J. Fischer, Working fluids for low-temperature organic Rankine cycles, Energy 32, pp 1210-1221, (2007)

12. H. Chen, D.Y. Goswami, E.K. Stefanakos, A review of thermodynamic cycles and working fluids for the conversion of low-grade heat, Renewable and Sustainable Energy Reviews, 14 (9), pp. 3059-3067, (2010)

13. W. Nowak, S. Wiśniewski, A concept to fuel the ORC power plant by heat sources of different temperatures, Thermodynamics in Science and Technology Proceedings of the 1-st International Congress on Thermodynamics, Part 2 L. Bogusławski (Editor) Poznań, pp. 877-886, (2011)

14. A. Borsukiewicz-Gozdur, Dual-fluid-hybrid power plant co-powered by low-temperature geothermal water. Geothermics 39, 170-176, (2010)

15. W. Nowak, S. Wiśniewski, A. BorsukiewiczGozdur, Siłownia parowa $\mathrm{z}$ wieloźródłowym zasilaniem, Archiwum energetyki, Vol. 42, no. 2,pp 103-112, (in Polish), (2012)

16. S. Wiśniewski, G. Sołtysik, W. Nowak, Evaluation of the effectiveness of one-cycle ORC power plant supplied by geothermal water from lower and middle Triassic reservoirs, using a wet and dry working fluids, Geological Exploration Technology, Geothermal Energy, Sustainable Development, Vol. 57, (261), pp. 37-45, (in Polish) (2018)

17. NISIT. RefProp 9.0, Standard Reference Database 23, Version 9.0, , Reference Fluid Therodynamic and Transport Properties. National Institute of Standards and Technology, Gaithersburg, MD, USA. (2010) 